\title{
Increasing Readiness to Learn: Benefits of Executive Function Training in Kindergarten Carry over to First Grade
}

\author{
Ahmet Esat Imal*, Bruce E. Wexler* \\ Yale University, New Haven, CT, USA \\ Email: ^ahmetesat.imal@yale.edu, ^bruce.wexler@yale.edu
}

How to cite this paper: Imal, A. E., \& Wexler, B. E. (2018). Increasing Readiness to Learn: Benefits of Executive Function Training in Kindergarten Carry over to First Grade. Creative Education, 9, 2662-2676. https://doi.org/10.4236/ce.2018.916201

Received: October 19, 2018

Accepted: December 3, 2018

Published: December 7, 2018

Copyright (c) 2018 by authors and Scientific Research Publishing Inc. This work is licensed under the Creative Commons Attribution International License (CC BY 4.0).

http://creativecommons.org/licenses/by/4.0/

\section{cc) (i) Open Access}

\begin{abstract}
Executive Function skills such as focused attention, inhibition or self-control, and working memory in preschool and kindergarten predict reading and math achievement in elementary school and beyond. A growing body of research indicates that these skills can be improved by repetitive practice of progressively more difficult tasks that require Executive Function. We report that children who participated in an integrated program of computer presented and physical exercises to improve Executive Function when in kindergarten then entered first grade with greater attention and self-control skills than their first grade classmates who had not participated in the program.
\end{abstract}

\section{Keywords}

Executive Function, Cognitive Training, School Readiness

\section{Introduction}

Executive function (EF) refers to cognitive abilities associated with frontal lobe maturation including sustained and focused attention, response inhibition, cognitive flexibility, working memory and planning (Jurado \& Rosselli, 2007). These operations are associated with similar or overlapping neural systems, and measures of each are often inter-correlated (Best, Miller, \& Naglieri, 2011; Blair \& Razza, 2007; Davidson, Amso, Anderson, \& Diamond, 2006). Development of EFs begins accelerating during preschool and continues through adolescence. Teachers have long recognized the importance of EF for success in school, and teacher ratings of focused attention and persistence in pre-school are associated with academic success in elementary school (Blair \& Razza, 2007; Martin \& De- 
bus, 1998).

Many studies using measures of $\mathrm{EF}$ in pre- $\mathrm{K}$ and $\mathrm{K}$ children have found strong associations with subsequent math and reading achievement in elementary school. The executive functions most consistently found to predict later academic success are attention, inhibition, and working memory. For example, those kindergarten children better able to wait as instructed before eating a piece of candy, or wait their turn when jointly building a tower, had better G1 math and reading outcomes, even when controlling for non-verbal intelligence and maternal education (von Suchodoletz, Trommsdorff, Heikamp, Wieber, \& Gollwitzer, 2009). The effect size (0.62) was larger than the effect of non-verbal intelligence (0.18). Longitudinal studies that together include hundreds of 5 years old children demonstrate robust associations between tests of inhibition and memory before entering kindergarten, and math and reading achievement in kindergarten (Blair \& Razza, 2007; Bull \& Scerif, 2001; Welsh, Nix, Blair, Bierman, \& Nelson, 2010; Willoughby, Magnus, Vernon-Feagans, Blair, \& Family Life Project, 2017). Similar studies in kindergarten children predict math and reading achievement throughout elementary school and beyond (Al Otaiba \& Fuchs, 2006; Best et al., 2011; Bull \& Scerif, 2001; Monette, Bigras, \& Guay, 2011; Vandenbroucke \& Baeyens, 2017). In a meta-analysis of six longitudinal studies involving over 30,000 students, attention skills in kindergarten, along with early math and reading schools, predicted math and reading achievement throughout elementary and middle school (Duncan et al., 2007). Moreover, children who have trouble learning math have particularly poor attention focus (Swanson, 2006).

In addition to emphasizing the importance of EF to school success (Blair \& Diamond, 2008; Diamond, 2012; Diamond \& Lee, 2011), Diamond and colleagues have evaluated an early school classroom curriculum created by $\mathrm{Vy}$ gotsky (1978) to train and improve EF (Diamond, Barnett, Thomas, \& Munro, 2007; Diamond \& Lee, 2011). In addition, they provide an overview of evidence showing that specific games, physical exercises and computer-presented neurocognitive exercises can improve EF in young children (Diamond, 2012). They note that these interventions have in common repeated practice and progressive challenges. They emphasize the potential value of such interventions in increasing ability to succeed in school. Other studies show that physical exercise increases neuroplasticity (Bechara, Lyne, \& Kelly, 2014; Hillman, Erickson, \& Kramer, 2008; Whiteman et al., 2014), but physical exercise has not been previously used as an integrated feature of cognitive training for children although it seems likely that increasing neuroplasticity through cognitively demanding physical exercise could potentially increase the impact of computer-presented exercises. In this report we describe a program of computer-presented cognitive exercises and specially designed physical cognitive training exercises used in kindergarten, and we will describe their effects on EF at the start of first grade.

We have previously reported that in preliminary studies, elementary school children who did the cognitive skills training (CST) program showed greater 
gains than comparison classes on the Flanker test of focused attention, the List-Sorting Test of Working Memory, the NWEA standardized test of reading, and subtests most related to EF from the Blue Ribbon standardized tests of reading and math (Wexler, 2013). Moreover, children who did more CST showed greater gains in New York state proficiency in reading than same age children in their school who spent less time training (Wexler, 2013). Subsequent analysis of data from over 1000 children showed highly significant pre to post training gains in attention, inhibition and working memory (Kavanaugh, Tuncer, \& Wexler, 2018). Perhaps most important, in a sample of over 500 third graders, classes receiving the CST showed significantly greater gains than comparison classes on school-administered tests of math and reading achievement demonstrating far-transfer real-world functional significance of the training-related cognitive gains (Wexler et al., 2016).

The present study focused specifically on whether benefits of CST in kindergarten carry over the summer break so as to increase learning skills that are important in first grade and predictive of math and reading achievement and future academic success in general. Several recent meta-analyses and reviews have raised important questions about whether the effects of computer based cognitive training programs are lasting and whether these programs lead to more general improvements in function beyond better performance on the training tasks or tests very similar to them (e.g. Melby-Lervag \& Hulme, 2013). Our work showing significant benefits on school-administered math and reading achievement tests (Wexler et al., 2016) and previous work by us and others showing transfer to employment gains in adult clinical populations (Belleville et al., 2017; Buonocore et al., 2018; Fiszdon, Bryson, Wexler, \& Bell, 2004; Garrido et al., 2017), among other studies, speak to the issue of generalization of benefit. We are not aware, however, of data related to the durability of training effects in healthy children. This is particularly important since this is a school-based program and it is well known that curricular content learning and skills like reading often show significant decline over the summer (Cooper, Nye, Charlton, Lindsay, \& Greathouse, 1996). If gains from CST in kindergarten are lost over the summer before the children enter first grade, it would suggest that the value of training in kindergarten is limited unless, perhaps, it is continued over the summer at home or in special programs.

To address these questions we took advantage of a naturalistic experiment. Kindergarten children in several elementary schools in one school district did the CST program during school year 2013-14 and were then given EF tests at the beginning of first grade in school year 2014-15. Some of their first grade classmates had not been in kindergartens where the CST was offered, thus providing a comparison group. All children in the first grade class, then, were given the EF tests at the same time in the same classrooms at the start of first grade, but some had had the CST in kindergarten and some had not. Our primary hypothesis was that children who did CST in kindergarten would have better performance on $\mathrm{EF}$ assessments at the beginning of first grade than their first grade classmates 
who had not done CST in kindergarten. Given the naturalistic nature of the experiment, we also evaluated two additional hypotheses that link possible cognitive function advantages in the intervention group at the start of first grade to the CST they did in kindergarten. Our secondary hypotheses were 1) that students who did the CST in kindergarten would show increases in EF immediately after completing training and 2) that the degree of improvement immediately after completing training in kindergarten would be positively correlated with EF scores at the beginning of first grade.

\section{Method}

\subsection{Participants}

170 kindergarten children in Fairfax County Public Schools participated in the CST during school year 2013-14 and then were available for assessment at the start of first grade in the Fall of school year 2014-15. In addition, all 97 of the participants' first grade classmates who had not participated in the CST in kindergarten were assessed for comparison at the same time. There were no selection or exclusion criteria for either group; all children in the classes were included. We do not have identifying or demographic information on individual children, but only $10 \%$ of children in the participating schools received free or reduced lunch indicating that the schools were not in poverty areas. All study procedures were reviewed and approved by the Yale University School of Medicine Human Investigations Committee. Since this was analysis of an anonymized archival data set, the study received a waiver of informed consent.

\subsection{Intervention}

Computer-Presented Cognitive Skills Training Exercises: Children did the cognitive skills training games as a group during the school day three days per week, 20 - 30 minutes per day over a period of 5 months. There were three games, each with 80 - 150 levels of difficulty. The first game (Figure 1) began with a yellow ball moving randomly across the screen and the child had to use the mouse to click on it whenever it turns red, thus exercising sustained attention. The ball moved faster following correct responses and slowed down after errors. As they either reached a preset high level of performance or stayed at a lower performance level without improvement for an extended period of time, the child was moved through progressive levels that layer in additional cognitive demands. On the next level in this game the ball sometimes turned blue (a foil) that is to be ignored, adding in response inhibition. Next, the target color randomly changed back and forth between blue and red, increasing the challenge of response inhibition and adding cognitive flexibility. The next levels required working memory as a ball was a target only if it changed to the same color twice in a row ("same as last") or changed to a different color ("different from last"). All rules were repeated with two and then three balls on the screen. In the second game (Figure 1), children clicked on butterflies carrying signs up the 
Computer and Physical Executive Function Training Games

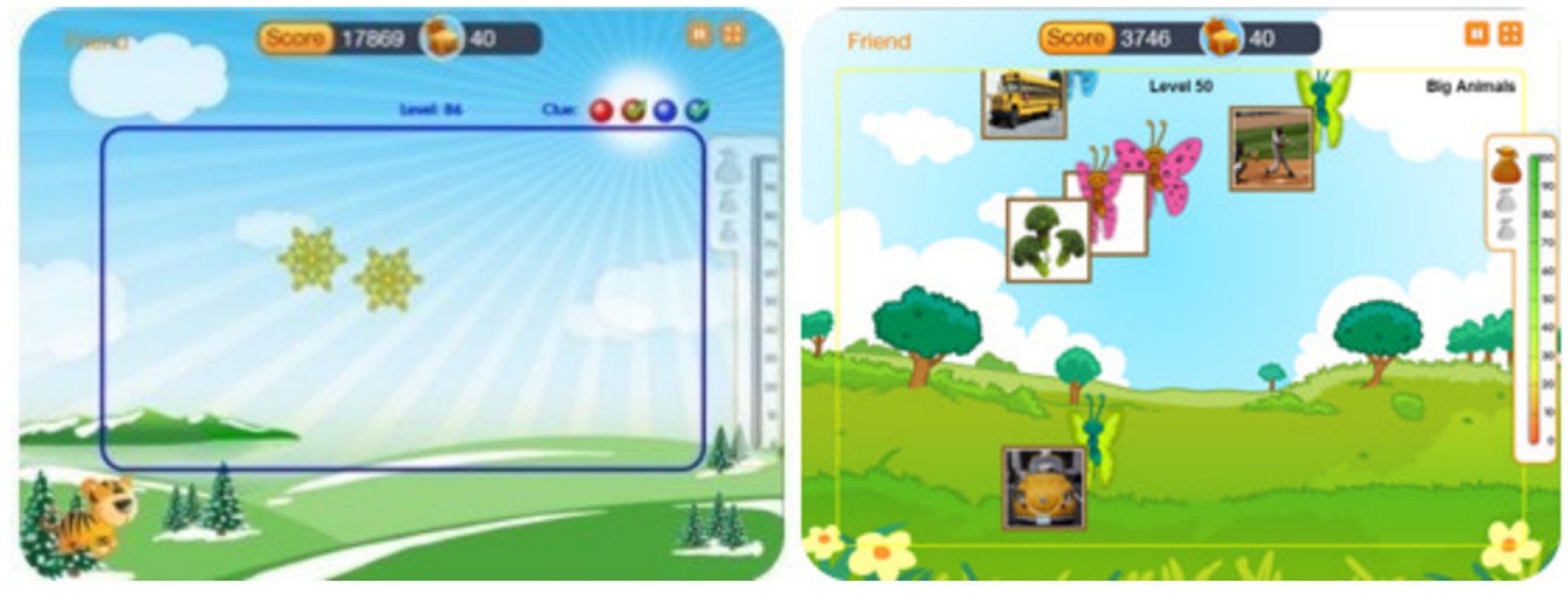

\begin{tabular}{|l|}
\hline Sustained Attention \\
\hline Inhibitory Control \\
\hline Speed of Information Processing \\
\hline Cognitive Flexibility \\
\hline Multiple Simultaneous Attention \\
\hline Working Memory \\
\hline Category Formation \& Use \\
\hline Pattern Recognition \& Use \\
\hline
\end{tabular}
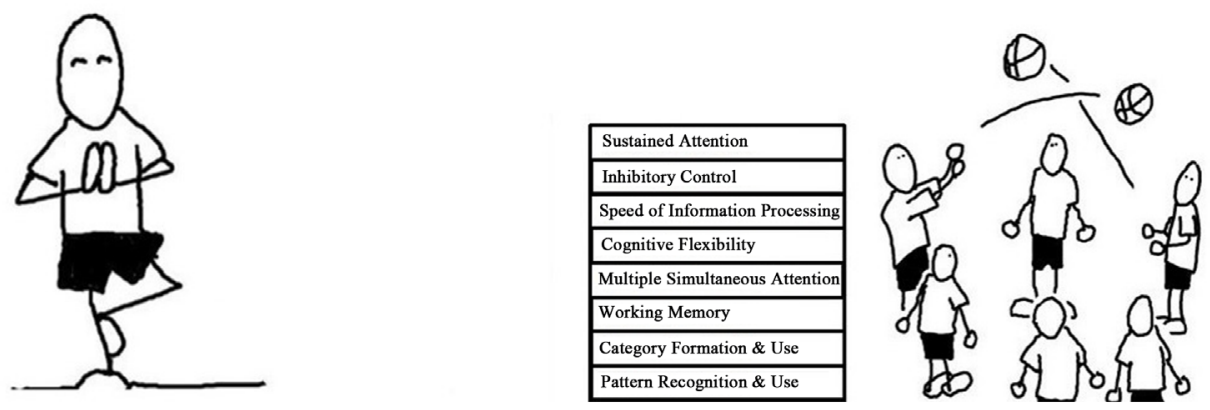

Figure 1. Examples of computer and physical exercises. Capture of game 1, two yellow balls moving across the screen (Top Left). Capture of game 2, butterflies carry 5 objects to be selected (Top Right). Illustration of yoga-like balancing with which cognitive functions are trained on the sidebar; standing on one leg, eyes closed, free leg in side position (Bottom Left). Illustration of controlled ball passing with which cognitive functions are trained on the sidebar; throwing and catching two balls with different rules (Bottom Right). Currently, game players use upgraded interfaces available online:

http://www.c8schools.com/program/cognitive-software/.

screen if the object on the sign was a member of a designated category (e.g., animals. furniture, tools, machines) that trained another aspect of executive function, use of category. With correct responses, the butterflies moved faster, and more butterflies were on the screen at the same time (from 1 to 6) which additiononally trained sustained attention and speed of processing. At higher levels, categories rotated, two categories were targets simultaneously, or the child had to find two objects on the screen that are in the same category aimed to train inhibition, cognitive flexibility and, to a limited extend, working memory. The third game required the child to figure out the rule that links a series of three objects and use this rule to choose a fourth object to complete the row. On initial levels the rules were very simple (e.g., "all objects the same color"). On subsequent levels rules were more complex (e.g., "all objects are different in shape) and include rotations of different shapes, number sequences, or trials of different types requiring set shifting. Time to respond became shorter with each correct 
response. Points earned for correct responses on all games were used each day to get rewards from a virtual store. In this game we trained pattern recognition and inductive thinking, as well as attention, cognitive flexibility, speed of processing and working memory.

Physical Exercises: Like the computer exercises, cognitive aspects of the physical exercises begin with sustained attention and response inhibition, and progressively layer in cognitive flexibility, multiple simultaneous attention and working memory. For example, initially children were each assigned their own space (e.g., within their own circle on the floor), attended to their own bodies and practiced yoga-like balancing poses (e.g., "brain-crane") (Figure 1). Next, they did controlled ball passing in pairs, group running games with rules that require planning, strategy and self-control, or response inhibition games like "Simon Says." Later they learned martial arts and dance sequences or threw two different colored bags to one another in circles of 5 - 6 children, with each color having a different sequence of individuals to whom it is thrown (Figure 1). Each day there was a varying mix of aerobic games, and group and individual focused exercises. Children did the physical exercises one or two days per week for 30 minutes for 5 months.

Measures of EF: EF outcomes were assessed with three web-based measures embedded in the CST computer program and automatically presented, administered and scored in the classroom. EF measurements started on the third day of the program to give teachers and students time to be familiar with the program and were given one per day for three days. Two tests (Flanker and Working Memory) followed precisely the design of tests in the NIH Toolbox of tests of EF (nihtoolbox.org). The fact that the tests are done in the classroom environment adds ecological validity to the scores. But since the testing environment is not controlled, and there are no direct observations of children while testing, test validity criteria are applied as part of the auto-scoring of all tests as described below. The first test was the Flanker Test of focused attention where the primary performance measure was reaction time on correct incongruent trials. In this task, children indicate by keyboard response the pointing direction (right or left) of the center arrow in a linear horizontal array of five arrows. On incongruent trials, the four "flanking" arrows point in the opposite direction of the central arrow. Following the procedure of the NIHTool box, there are 19 congruent trials and 11 incongruent trials. Response times longer than $4500 \mathrm{msec}$ on incongruent trials and $3500 \mathrm{msec}$ on congruent trials were so slow as to suggest classroom distraction or momentary disengagement from the test, and those trials were excluded. Response times faster than $150 \mathrm{msec}$ suggested random responding and such trials were also excluded. Tests with more than 4 incongruent "too slow" trials, more than 7 congruent "too slow" trials, more than 4 "too fast" trials, less than $75 \%$ correct on the congruent trials or fewer than 8 correct incongruent trials were considered invalid because there were not enough valid trials to reliably evaluate performance and because they suggested repeated distraction or disengagement.. Finally, tests were considered invalid if average reac- 
tion time on correct incongruent trials was slower than $3400 \mathrm{msec}$ or faster than $250 \mathrm{msec}$, values more than two standard deviations from the mean in our national data set of approximately 10,000 children and indicative of outlier performance, general inattention to test, or random responding. The second test was the List Sorting Working Memory Test. Subjects are shown a series of animals or household objects. They then have to click on the objects they have just seen in a grid of 16 objects, clicking them in order from smallest to largest rather than the order in which they were presented. The test starts with a list of $2 \mathrm{ob}-$ jects. If the subject completes the list accurately, list length is increased by one. If they err, the same length list is repeated. Two failed attempts at the same list length ends the test. The score is the sum of correct list lengths. In part one, trials of animals and household objects alternate. In part two, animals and household objects are presented in the same trial, and subjects have to reorder the animals first and then the household objects. If children were unable to report back two items in correct order, we considered it possible that they did not understand or engage with the test and their scores were considered invalid and not included in the analyses. The third test is a Go/No-Go test of response inhibition. Subjects are instructed to press the space bar whenever a "Go" stimulus is presented but not when a "No-Go" stimulus is presented. There are three blocks with different stimuli, 50 stimuli per block with 40 Go and 10 No-Go trials, randomized in sets of 10 with 8 Go and 2 No-Go in each set. In the first block "P" is the go stimulus and " $\mathrm{R}$ " is the no-go stimulus. In the second block this is reversed. In the third block, pictures of furniture are the go trials and pictures of foods like cake and ice cream are the no-go stimuli. Stimuli are presented for 400 msec with a $1400 \mathrm{msec}$ response window after stimulus offset. Errors are indicated by display of a large red "X." Trials with response times greater than 2000 msec were eliminated since the response was after presentation of another stimulus and so slow as to suggest the child may have been distracted by other children or otherwise not engaged. Trials with response times less than 150 msec. were eliminated because response was too fast to confidently be related to the stimulus. Tests with less than $85 \%$ correct response to Go-Trials fail to establish the consistent response bias required to measure response-inhibition, and through general inattention or poor accuracy artificially elevate the rate of No-Go trials correctly skipped. Such tests were therefore deemed invalid. Tests with more than 10 "too slow" trials or more than 15 "too fast" trials were also considered invalid because of concern that the children were attending inconsistently or responding randomly, and therefore not establishing the consistent response bias needed to assess response inhibition. Absences from the program on a day that a pre- or post-test was administered and varying numbers of children who met test-validity criteria for each test led to different numbers of subjects in the analyses for each test. During kindergarten testing in school year 2013-14, $49 \%$ of tests met validity criteria to include in the analyses. In 2014-2015, the tests were improved by enhanced clarity of instructions and visual elements, which together with the fact that the child fen were a year older, led to $72 \%$ of 
the tests being considered valid and reliable enough to include in the analyses. The results were not significantly different when ignoring validity criteria, with greater variability and noise compromising the signal but larger samples strengthening it. When providing information about individual children to schools for pedagogic planning, we think it is essential to only base reports on tests that meet strict validity criteria. Since our samples are relatively large, we have followed that same process in these group analyses. While test improvements added to the proportion of valid tests, the changes make it impossible to compare EF measurements of 2014-2015 with EF measurements of 2013-2014 in children who had both.

Statistical Analyses: Our primary hypothesis was that children who had cognitive training during kindergarten would have higher cognitive skills scores at the beginning of first grade than their first-grade classmates who did not have training during kindergarten. This was evaluated with three independent t-tests between the groups, using a single performance index for each of the three cognitive function tests based on recommendations in the NIH Toolbox and the usual practice in the research literature. Secondary and exploratory analyses sought to confirm that children receiving the cognitive training during kindergarten did in fact show gains on the cognitive function tests before and after training while in kindergarten, and to evaluate the degree to which these improvements in kindergarten were related to their scores in first grade. Paired t-tests and correlation analyses were used, respectively. The goals of the secondary and exploratory analyses were to provide additional confidence that between group differences observed in first grade were related to training during kindergarten.

\section{Results}

\subsection{Training in Kindergarten}

Comparison to scores before and after CST in children who received CST in kindergarten showed highly significant improvements in focused attention, inhibition, and working memory. Average reaction time on correct incongruent Flanker trials decreased from $1804 \mathrm{msec}(\mathrm{SD}=437 \mathrm{msec})$ to $1280 \mathrm{msec}(\mathrm{SD}=$ $266 \mathrm{msec})(\mathrm{n}=31)(\mathrm{t}(30)=5.5, \mathrm{p}=0.000003)$. Average working memory score increased from $8.1(\mathrm{SD}=4.16)$ to $12.8(\mathrm{SD}=9.2)(\mathrm{n}=29)(\mathrm{t}(28)=2.62, \mathrm{p}=$ 0.007). Average percent correct on No-Go trials on the Go/No-Go test increased from $44 \%(S D=16 \%)$ to $55 \%(S D=20 \%)(n=16)(t(15)=1.92, \mathrm{p}=0.037)$.

\subsection{EF in First Grade Children Who Did and Did Not Do Cognitive Skills Training in Kindergarten}

Average reaction times on the correct incongruent flanker trials for first graders not exposed to CST and those who had CST were $1305 \mathrm{msec}$ (SD = $505 \mathrm{msec}$ ) (n $=81)$ vs. $1095 \mathrm{msec}(\mathrm{SD}=384 \mathrm{msec})(\mathrm{n}=126)(\mathrm{t}(125)=3.43, \mathrm{p}=0.0004) . \mathrm{On}$ the Go/No-Go test, average percentage of "No-Go" trials correctly skipped was 
$40 \%(\mathrm{SD}=22 \%)(\mathrm{n}=65)$ vs. $49 \%(\mathrm{SD}=23 \%)(\mathrm{n}=106)(\mathrm{t}(105)=2.70, \mathrm{p}=.004)$

(Figure 2). The two groups did not differ in average WM score, $17.3(\mathrm{SD}=11.5)$ $(\mathrm{n}=74)$ vs. $18.5(\mathrm{SD}=12)(\mathrm{n}=114)(\mathrm{p}=0.24)$.

\subsection{Association between CST-Related Improvement in Kindergarten and EF When Entering First Grade}

When children who had CST training in kindergarten entered first grade, they had higher scores than their first grade classmates who did not do CST in kindergarten in both focused attention and self-control. In the small subsample of children with all relevant data points, the correlation between improvement in kindergarten in self-control and self-control scores upon entering first grade was $\mathrm{r}=0.73(\mathrm{t}(7)=2.99, \mathrm{p}=0.01)$, with differences among children in baseline scores in kindergarten used as a covariant. The correlation between improvement in kindergarten and first grade scores in focused attention was also in the predicted direction, with children who showed greater gains in kindergarten having better scores when entering first grade, $r=0.27$, but did not reach statistical
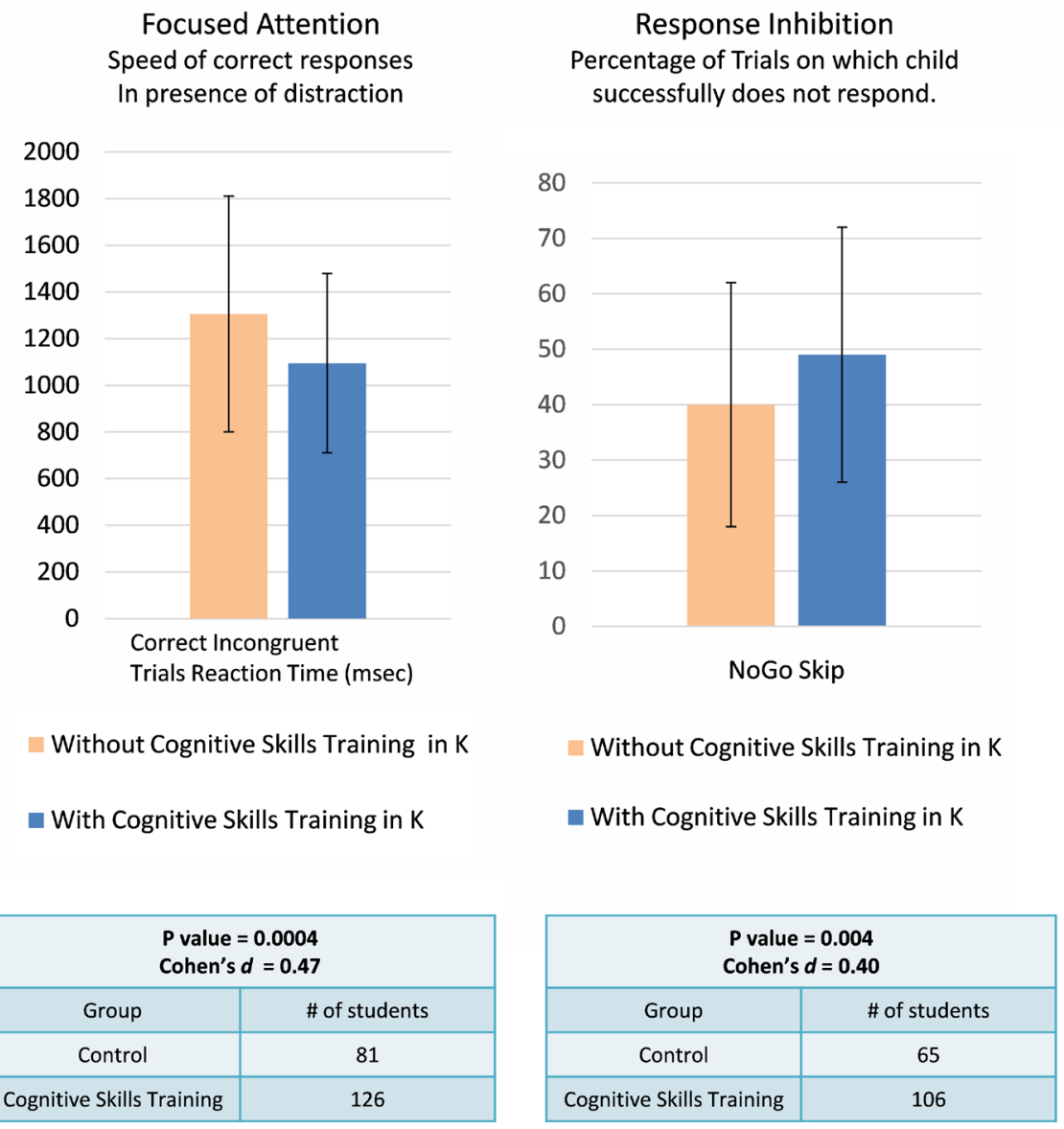

Figure 2. Executive function measures in Grade 1. Left-sided bars are reaction times of correct incongruent trial reaction of students who did and did not do cognitive skills training in kindergarten. Right-sided bars are percentages of "No-Go" trials correctly skipped of students who did and did not do cognitive skills training in kindergarten. Student numbers, $p$ values and effect sizes are on the below. 
significance in the small sample $(t(11)=0.91, p=0.19)$. The two groups did not differ in working memory at the start of first grade, and there was no suggestion of an association between CST-related improvement in kindergarten and first grade scores $(r=0.03)$.

\section{Discussion}

It is well established that EF cognitive abilities of focus, inhibition and memory in kindergarten predict academic success throughout elementary school (see introduction). Other research shows that these skills can be improved by a variety of training exercises (Diamond, 2012). Our findings are consistent with this previous work in that children who did CST in kindergarten showed improvement in EF after training. We add to previous work by showing that when these children enter first grade they show greater ability to focus attention on the Flanker test and inhibit responses on a Go/No-Go test than classmates who did not receive CST in kindergarten. These are the same tests used in prospective studies showing that ability to focus attention and inhibit responses predict later school success (Welsh et al., 2010). Our data thus suggest that school readiness and academic outcomes may be enhanced by formal and rigorous cognitive skill training in kindergarten. Such training might be particularly important for children who come to school not having had the stimulation necessary to promote development of cognitive skills necessary for success in school. For example, poverty and exposure to trauma are both associated with lower EF skills and poorer academic performance (DePrince, Weinzierl, \& Combs, 2009; Welsh et al., 2010). The program used is a web-based computer-presented cognitive skills training program, making it easy to disseminate for wide use. The technology allows for rapid and powerful adjustment of the training to match the skill level of the individual user.

The primary limitation of the study is that it is not a randomized controlled study of children within the same kindergartens but relies instead on a naturalistic comparison group of children who attended different kindergartens than the CST group. Thus, it is possible that children in the comparison group had lower scores in focused attention and response inhibition at the start of first grade because they had inferior kindergarten experiences in general, were delayed in development by family relocations as reflected in their now being in a new school, or other factors. For several reasons, however, we think it is more likely that the higher EF scores at the start of first grade in the group that had CST in kindergarten are related to the CST. First, there is very extensive neuroscience research demonstrating that the brain responds to repetitive targeted stimulation of information processing neural systems with activity-mediated changes in structure and function (e.g., de Villers-Sidani et al., 2010; Mahncke, Bronstone, \& Merzenich, 2006; Wexler \& Bell, 2005). Therefore, it is entirely expected from what is known about the brain that appropriate CST can increase targeted cognitive skills. Second, tests of EF before and after the CST in kindergarten did in fact 
show increases in the targeted cognitive skills, i.e., the intervention did do what the neuroscience research predicted it would do. Moreover, and thirdly, the more a child improved in self-control after CST in kindergarten, the higher their self-control score was in first grade, directly linking the CST in kindergarten to the higher scores in first grade. A similar but less robustcorrelation was found between the amount of improvement in attention after CST in kindergarten and attention scores in first grade. Fourth, in assessment at the start of first grade, working memory scores did not differ between the CST and comparison groups. WM increases steadily from kindergarten through elementary school (Gathercole, Pickering, Ambridge, \& Wearing, 2004), so the nearly identical scores on the WM test suggests that there are no general developmental differences between the CST and comparison groups. Thus, given that neuroscience research predicts that CST can increase cognitive skills, that tests before and after CST during kindergarten demonstrate gains in cognitive skills, that greater CST-related improvement in kindergarten was associated with higher EF scores in first-grade, and that WM test scores at the start of first grade indicate that there is not a general developmental difference between the CST and comparison groups, it seems to us highly likely that the observed differences between groups at the start of first grade are carry-over effects of the CST in kindergarten rather than the result of some other unknown differences in experiences between the groups prior to first grade. But the possibility remains that the differences observed in first grade have sources other than the CST training in kindergarten and indicates the need for caution when drawing conclusions and the value of replication studies. Another concern would be the participants took the tests of the EF twice caused a practice effect. We think this was very unlikely, because when the Flanker and Go/No-Go tests were repeated with a two-week inter-test interval, performance increases $3 \%$ on the Flanker and $1 \%$ on the Go/No-Go test (Kavanaugh et al., 2018). There was more than four months between the testing in first grade and the preceding test and performance differences between the children who did and did not do the Activate program in kindergarten were $16.1 \%$ on the Flanker and $22.5 \%$ on the Go/No-Go test.

It is also noteworthy that there was no evidence of carryover effects in WM. WM is the most complex of the three EF cognitive skills trained and assessed, and the List Sorting WM test incorporates the more basic cognitive skills of focused attention and response inhibition. It may be that consolidation of the pro-performance effects of CST in more complex neurocognitive processes requires longer training.

\section{Conclusion}

Cognitive skills training in kindergarten is associated with evidence of increased focus and self-control when children enter first grade. These EF skills are essential for good learning, so CST in kindergarten is a possible way to increase "school readiness." Previous research has established that compromised EF de- 
velopment prior to starting school probably contributes to academic achievement gaps associated with poverty. The present study provides pilot data supporting the potential role of early cognitive skills training to help children from disadvantaged backgrounds gain greater benefit from school, but further research is needed. Limitations in study design, however, leave open the possibility that aspects of the kindergarten experience other than the CST training could have led to the observed group differences upon entering first grade.

\section{Conflicts of Interest}

AEI has no competing financial interests. BEW is Chief Scientist at and a shareholder in the Yale startup company C8 Sciences that developed and markets the brain-training games used in the research reported in this paper.

\section{Ethical Approval}

All procedures performed in studies involving human participants were in accordance with the ethical standards of the institutional and/or national research committee and with the 1964 Helsinki declaration and its later amendments or comparable ethical standards.

\section{Informed Consent}

Since this was analysis of an anonymized archival data set, the study received a waiver of informed consent.

\section{References}

Al Otaiba, S., \& Fuchs, D. (2006). Who Are the Young Children for Whom Best Practices in Reading Are Ineffective? An Experimental and Longitudinal Study. Journal of Learning Disabilities, 39, 414-431. https://doi.org/10.1177/00222194060390050401

Bechara, R. G., Lyne, R., \& Kelly, A. M. (2014). BDNF-Stimulated Intracellular Signalling Mechanisms Underlie Exercise-Induced Improvement in Spatial Memory in the Male Wistar Rat. Behavioural Brain Research, 275, 297-306. https://doi.org/10.1016/j.bbr.2013.11.015

Belleville, S., Fouquet, C., Hudon, C., Zomahoun, H. T. V., Croteau, J., \& Consortium for the Early Identification of Alzheimer's Disease-Quebec (2017). Neuropsychological Measures that Predict Progression from Mild Cognitive Impairment to Alzheimer's Type Dementia in Older Adults: A Systematic Review and Meta-Analysis. Neuropsychology Review, 27, 328-353. https://doi.org/10.1007/s11065-017-9361-5

Best, J. R., Miller, P. H., \& Naglieri, J. A. (2011). Relations between Executive Function and Academic Achievement from Ages 5 to 17 in a Large, Representative National Sample. Learning and Individual Differences, 21, 327-336.

https://doi.org/10.1016/j.lindif.2011.01.007

Blair, C., \& Diamond, A. (2008). Biological Processes in Prevention and Intervention: The Promotion of Self-Regulation as a Means of Preventing School Failure. Development and Psychopathology, 20, 899-911. https://doi.org/10.1017/S0954579408000436

Blair, C., \& Razza, R. P. (2007). Relating Effortful Control, Executive Function, and False Belief Understanding to Emerging Math and Literacy Ability in Kindergarten. Child 
Development, 78, 647-663. https://doi.org/10.1111/j.1467-8624.2007.01019.x

Bull, R., \& Scerif, G. (2001). Executive Functioning as a Predictor of Children's Mathematics Ability: Inhibition, Switching, and Working Memory. Developmental Neuropsychology, 19, 273-293. https://doi.org/10.1207/S15326942DN1903_3

Buonocore, M., Spangaro, M., Bechi, M., Baraldi, M. A., Cocchi, F., Guglielmino, C. et al. (2018). Integrated Cognitive Remediation and Standard Rehabilitation Therapy in Patients of Schizophrenia: Persistence after 5 Years. Schizophrenia Research, 192, 335-339. https://doi.org/10.1016/j.schres.2017.05.022

Cooper, H., Nye, B., Charlton, K., Lindsay, J., \& Greathouse, S. (1996). The Effects of Summer Vacation on Achievement Test Scores: A Narrative and Meta-Analytic Review. Review of Educational Research, 66, 227-268. https://doi.org/10.3102/00346543066003227

Davidson, M. C., Amso, D., Anderson, L. C., \& Diamond, A. (2006). Development of Cognitive Control and Executive Functions from 4 to 13 Years: Evidence from Manipulations of Memory, Inhibition, and Task Switching. Neuropsychologia, 44, 2037-2078. https://doi.org/10.1016/j.neuropsychologia.2006.02.006

de Villers-Sidani, E., Alzghoul, L., Zhou, X., Simpson, K. L., Lin, R. C., \& Merzenich, M. M. (2010). Recovery of Functional and Structural Age-Related Changes in the Rat Primary Auditory Cortex with Operant Training. Proceedings of the National Academy of Sciences of the United States of America, 107, 13900-13905.

https://doi.org/10.1073/pnas.1007885107

DePrince, A. P., Weinzierl, K. M., \& Combs, M. D. (2009). Executive Function Performance and Trauma Exposure in a Community Sample of Children. Child Abuse \& Neglect, 33, 353-361. https://doi.org/10.1016/j.chiabu.2008.08.002

Diamond, A. (2012). Activities and Programs that Improve Children's Executive Functions. Current Directions in Psychological Science, 21, 335-341. https://doi.org/10.1177/0963721412453722

Diamond, A., \& Lee, K. (2011). Interventions Shown to Aid Executive Function Development in Children 4 to 12 Years Old. Science, 333, 959-964. https://doi.org/10.1126/science.1204529

Diamond, A., Barnett, W. S., Thomas, J., \& Munro, S. (2007). Preschool Program Improves Cognitive Control. Science, 318, 1387-1388. https://doi.org/10.1126/science.1151148

Duncan, G. J., Dowsett, C. J., Claessens, A., Magnuson, K., Huston, A. C., Klebanov, P., Japel, C. et al. (2007). School Readiness and Later Achievement. Developmental Psychology, 43, 1428-1446. https://doi.org/10.1037/0012-1649.43.6.1428

Fiszdon, J. M., Bryson, G. J., Wexler, B. E., \& Bell, M. D. (2004). Durability of Cognitive Remediation Training in Schizophrenia: Performance on Two Memory Tasks at 6-Month and 12-Month Follow-Up. Psychiatry Research, 125, 1-7. https://doi.org/10.1016/j.psychres.2003.10.004

Garrido, G., Penades, R., Barrios, M., Aragay, N., Ramos, I., Valles, V., Vendrell, J. M. et al. (2017). Computer-Assisted Cognitive Remediation Therapy in Schizophrenia: Durability of the Effects and Cost-Utility Analysis. Psychiatry Research, 254, 198-204. https://doi.org/10.1016/j.psychres.2017.04.065

Gathercole, S. E., Pickering, S. J., Ambridge, B., \& Wearing, H. (2004). The Structure of Working Memory from 4 to 15 Years of Age. Developmental Psychology, 40, 177-190. https://doi.org/10.1037/0012-1649.40.2.177

Hillman, C. H., Erickson, K. I., \& Kramer, A. F. (2008). Be Smart, Exercise Your Heart: 
Exercise Effects on Brain and Cognition. Nature Reviews Neuroscience, 9, 58-65. https://doi.org/10.1038/nrn2298

Jurado, M. B., \& Rosselli, M. (2007). The Elusive Nature of Executive Functions: A Review of Our Current Understanding. Neuropsychology Review, 17, 213-233. https://doi.org/10.1007/s11065-007-9040-Z

Kavanaugh, B., Tuncer, O. F., \& Wexler, B. E. (2018). Measuring and Improving Executive Function in the Classroom.

Mahncke, H. W., Bronstone, A., \& Merzenich, M. M. (2006). Brain Plasticity and Functional Losses in the Aged: Scientific Bases for a Novel Intervention. Progress in Brain Research, 157, 81-109. https://doi.org/10.1016/S0079-6123(06)57006-2

Martin, A. J., \& Debus, R. L. (1998). Self-Reports of Mathematics Self-Concept and Educational Outcomes: The Roles of Ego-Dimensions and Self-Consciousness. British Journal of Educational Psychology, 68, 517-535. https://doi.org/10.1111/j.2044-8279.1998.tb01309.x

Melby-Lervag, M., \& Hulme, C. (2013). Is Working Memory Training Effective? A Meta-Analytic Review. Developmental Psychology, 49, 270-291. https://doi.org/10.1037/a0028228

Monette, S., Bigras, M., \& Guay, M. C. (2011). The Role of the Executive Functions in School Achievement at the End of Grade 1. Journal of Experimental Child Psychology, 109, 158-173. https://doi.org/10.1016/j.jecp.2011.01.008

Swanson, H. L. (2006). Cognitive Processes That Underlie Mathematical Precociousness in Young Children. Journal of Experimental Child Psychology, 93, 239-264. https://doi.org/10.1016/j.jecp.2005.09.006

Vandenbroucke, L. V. K., \& Baeyens, D. (2017). The Development of Executive Functioning across the Transition to First Grade and Its Predictive Value for Academic Achievement. Learning and Instruction, 49, 103-112.

https://doi.org/10.1016/j.learninstruc.2016.12.008

Von Suchodoletz, A., Trommsdorff, G., Heikamp, T., Wieber, F., \& Gollwitzer, P. M. (2009). Transition to School: The Role of Kindergarten Children's Behavior Regulation. Learning and Individual Differences, 19, 561-566. https://doi.org/10.1016/j.lindif.2009.07.006

Vygotsky, L. (1978). Interaction between Learning and Development. In M. Gauvain, \& M. Cole (Eds.), Readings on the Development of Children (pp. 34-40). New York: Scientific Academic Books.

Welsh, J. A., Nix, R. L., Blair, C., Bierman, K. L., \& Nelson, K. E. (2010). The Development of Cognitive Skills and Gains in Academic School Readiness for Children from Low-Income Families. Journal of Educational Psychology, 102, 43-53. https://doi.org/10.1037/a0016738

Wexler, B. E. (2013). Integrated Brain and Body Exercises for ADHD and Related Problems with Attention and Executive Function. International Journal of Gaming and Computer-Mediated Simulations, 5, 17.

Wexler, B. E., \& Bell, M. D. (2005). Cognitive Remediation and Vocational Rehabilitation for Schizophrenia. Schizophrenia Bulletin, 31, 931-941. https://doi.org/10.1093/schbul/sbi038

Wexler, B. E., Iseli, M., Leon, S., Zaggle, W., Rush, C., Goodman, A., Bo, E. et al. (2016). Cognitive Priming and Cognitive Training: Immediate and Far Transfer to Academic Skills in Children. Scientific Reports, 6, Article No. 32859.

https://doi.org/10.1038/srep32859 
Whiteman, A. S., Young, D. E., He, X., Chen, T. C., Wagenaar, R. C., Stern, C. E., \& Schon, K. (2014). Interaction between Serum BDNF and Aerobic Fitness Predicts Recognition Memory in Healthy Young Adults. Behavioural Brain Research, 259, 302-312. https://doi.org/10.1016/j.bbr.2013.11.023

Willoughby, M. T., Magnus, B., Vernon-Feagans, L., Blair, C. B., \& Family Life Project, I. (2017). Developmental Delays in Executive Function from 3 to 5 Years of Age Predict Kindergarten Academic Readiness. Journal of Learning Disabilities, 50, 359-372.

https://doi.org/10.1177/0022219415619754 